\title{
Las ideas del joven Prebisch
}

\section{Adolfo Gurrieri*}

\section{Introducción}

Prebisch llegó a la CEPAL por primera vez en 1949 para escribir un informe en el cual presentó su opinión acerca de los principales problemas que enfrentaba en ese entonces el desarrollo económico de América Latina (Prebisch, 1949). Contratado como consultor externo, no contó con el apoyo de otros miembros de la institución para elaborarlo ni tuvo mucho tiempo para hacerlo, de modo que dicho informe fue expresión de ideas anteriores a su llegada a la institución. Como el contenido de ese trabajo provocó un gran impacto en los medios académicos y políticos de la región, siendo considerado un pilar fundacional del pensamiento estructuralista, se ha planteado a menudo cuándo y por qué motivos Prebisch incorporó aquellas ideas a su pensamiento. ${ }^{1}$

En 1949 Prebisch ya tenía una dilatada carrera como académico y funcionario público y era, según Furtado, "el único economista latinoamericano de renombre internacional" (Furtado, 1985, p. 58). Sus pri-

\footnotetext{
* Ex Director de la División de Desarrollo Social de la CEPAL (a.gurrieri@mi-mail.cl). El autor agradece a Edgar Dosman el haberle permitido acceder a los borradores de algunos capítulos de la biografía de Prebisch que está preparando, los que fueron un gran estímulo para escribir el presente artículo.

1 Esta cuestión es diferente de otra, también importante pero no considerada en este artículo: si dichas ideas fueron o no originales de Prebisch y cuáles habrían sido las fuentes en que se nutrió. Sobre este aspecto, véase Love (1994 y 1999).
}

meros escritos datan de 1920, pero la opinión corriente es que durante los años veinte fue un convencido neoclásico y muy poco existe en ellos que pueda haber servido de base al informe de 1949. Sólo a consecuencia de la crisis que se inicia en 1929 habría comenzado a abandonar su neoclasicismo y buscar nuevas interpretaciones del proceso económico y políticas heterodoxas para reorientarlo. ${ }^{2}$ El que Prebisch haya confirmado a menudo esa secuencia simple en dos momentos debe haber influido para que fuese aceptada sin mayor cuestionamiento y no se profundizara el estudio de su pensamiento durante los años veinte (Prebisch, 1983).

Sin embargo, una atenta lectura de sus escritos de esos años muestra que la continuidad de sus ideas fue mucho mayor que la supuesta, por lo que resulta muy simplista dividir su evolución en dos momentos -ortodoxo y heterodoxo_- separados por la crisis de 1929. Prebisch mismo, cuando hilaba más fino, reconocía que los años veinte no habían sido pura ortodoxia. Por ejemplo, al referirse en una entrevista a los primeros artículos que escribió señaló: "En esos artículos hice un esfuerzo para interpretar con mis propios ojos y no

\footnotetext{
2 "Cuando Prebisch comenzó su carrera de economista y profesor, al cerrar el decenio de 1920, era ardiente partidario de las teorías neoclásicas. La gran depresión de los años treinta - la primera gran crisis del capitalismo - fue la causa primaria de la conversión de Prebisch" (Sprout, 1992, p. 188). Opiniones similares pueden encontrarse en muchos otros autores.
} 
con teoría económica elaborada desde fuera los fenómenos de la realidad. Atribuí gran importancia al balance de pagos... Comencé a entender la vulnerabilidad externa de la Argentina en ese momento. Esto ocurrió durante 1921 a 1923" (González y Pollock, 1991, p. 458). El que Prebisch haya confirmado a menudo esa secuencia simple en dos momentos claramente contrapuestos debe haber influido para que fuese dada por supuesta por aquellos que han estudiado su pensamiento, con la consecuencia ya mencionada de que no profundizaron el estudio de los años veinte.

Por lo tanto, el propósito de este artículo es mostrar que desde sus primeros trabajos, escritos en 1921, Prebisch comenzó a configurar el esquema de ideas que formuló en 1949 al llegar a la CEPAL. Asimismo, subrayar que no necesitó pasar por la experiencia de la crisis de 1929 para advertir los defectos del patrón primario exportador, pues éstos le resultaron evidentes a comienzos del decenio de 1920, cuando el proceso económico argentino era considerado un ejemplo de crecimiento exitoso. El brutal impacto de la crisis le sirvió para confirmar que no se había equivocado respecto a aquellos defectos, abandonar de manera definitiva su confianza en el patrón oro como criterio básico de manejo de la política económica y esforzarse por encontrar nuevos caminos que permitieran mejorar el nivel de vida de la población.

\section{Las principales ideas presentadas en el infor- me de 1949}

Sería imposible rastrear los orígenes de las principales ideas presentadas en el informe de 1949 sin antes haberlas enunciado, aunque fuese de manera extremadamente sintética. En dicho informe Prebisch formula los lineamientos de una estrategia para impulsar el desarrollo económico de América Latina, entendido como proceso orientado a mejorar el nivel de vida de la población mediante el incremento sistemático de la productividad. ${ }^{3} \mathrm{Su}$ tesis principal con respecto a la orientación de dicha estrategia es que ella no tendrá éxito si la actividad económica se concentra en torno a la producción y exportación de productos primarios a los centros industriales, por lo que resulta indispensable impulsar la industrialización. Como es sabido, el

\footnotetext{
${ }^{3}$ El informe de 1949 también puede ser analizado como siendo la base de la teoría estructuralista del subdesarrollo. Por supuesto, ambas perspectivas son válidas y se alimentan mutuamente. Los trabajos de Octavio Rodríguez constituyen el mayor aporte en esta dirección. Véase, por ejemplo, Rodríguez (2001a y 2001b).
}

patrón primario exportador había perdido su dinamismo a consecuencia de las dificultades impuestas al comercio internacional por la gran crisis y la Segunda Guerra y, aunque los efectos negativos de tales procesos ya estaban terminando, Prebisch no cree probable que pudiese ser retomado debido a la política proteccionista aplicada por los Estados Unidos desde 1930, que había reducido la demanda externa y la afluencia de capitales. Dada la importancia de este país como centro cíclico principal, concluye que dicha política impone condiciones que no permiten restablecer un funcionamiento de la economía mundial compatible con el patrón primario exportador. De todos modos, aunque Estados Unidos cambiase su política hacia el resto del mundo, y se expandiera nuevamente el comercio internacional y el movimiento de capitales, no sería conveniente que los países de América Latina retornasen al patrón primario exportador porque conlleva tres aspectos negativos. Primero, en tanto países primario-exportadores, sus procesos económicos son un reflejo de aquellos de los países industriales, lo que les somete a las fluctuaciones de éstos y les produce una considerable vulnerabilidad externa. Segundo, cuando el sistema económico mundial ha estado compuesto por países industriales y primario-exportadores el ingreso generado por el conjunto del sistema a raíz del aumento de la productividad tiende a concentrarse en los países industriales porque históricamente la relación de precios del intercambio entre productos industriales y primarios se ha movido a favor de ésos; tal cosa se debe, en última instancia, al papel subordinado que la producción primaria tiene en relación a la industrial en el proceso productivo del conjunto del sistema. Tercero, en la mayor parte de los países de la región las actividades primario-exportadoras no han sido ni serán capaces de incorporar a la creciente fuerza de trabajo y aumentar de manera sistemática su productividad.

Estas son las razones básicas por las cuales Prebisch sostiene que los países de América Latina no deben basar su desarrollo económico en el patrón primario exportador y lo que propone a cambio es una estrategia en la cual la industrialización juegue un papel decisivo. Sin embargo, aclara que su crítica se dirige a un tipo de desarrollo centrado en la producción y exportación de bienes primarios pero no a estas actividades en sí mismas, porque ellas deben formar parte importante de la nueva estrategia. Al respecto expresa que la industrialización no eliminará la restricción externa, por lo que para crecer sin desequilibrar el balance de pagos será necesario impulsar de manera 
decidida las exportaciones de productos primarios. Aun más, reconociendo la diversidad de situaciones nacionales, afirma que cada país deberá escoger la combinación sectorial que le resulte más conveniente al objetivo principal, que es el mejoramiento del nivel de vida de la población. Le preocupa que el sectorialismo primario-exportador sea reemplazado por otro basado en la industria; los desarrollos sectoriales son medios y no fines. Pese a que expuso sus ideas con mucha claridad y de manera reiterada, a menudo se les ha distorsionado, sea por ignorancia o defensa de intereses, presentándolas como si expresaran un industrialismo a ultranza y subestimaran, y aun menospreciaran, las actividades primarias. ${ }^{4}$

Prebisch presenta varias ideas acerca de los medios y condiciones necesarios para impulsar esta nueva estrategia de desarrollo, dos de los cuales destacan sobre los demás. Por un lado, subraya la necesidad de combinar la procura del desarrollo con los equilibrios monetario, fiscal y del sector externo. Rechaza que el manejo de la política macroeconómica se guíe por los criterios automáticos del patrón oro, porque ellos han demostrado ser procíclicos cuando lo que se necesita es aminorar las fluctuaciones; es indispensable la intervención deliberada de las autoridades públicas para que ese manejo sea ordenado $\mathrm{y}$, a la vez, responda a las necesidades del desarrollo. Por otro, recalca que el desarrollo requiere un enorme esfuerzo de ahorro interno y un incremento considerable de la proporción de él que se utiliza en inversiones reproductivas. De manera explícita rechaza la idea de utilizar la inflación como mecanismo de capitalización porque presiona sobre el balance de pagos y es regresiva en cuanto a la distribución del ingreso; es un ahorro forzado impuesto a la mayoría de la población en favor de unos pocos sin que exista ninguna certeza de que éstos utilizarán sus crecientes ingresos de un modo productivo. Asimismo, aunque piensa que la utilización de ahorro externo será indispensable dada la carencia de ahorro interno en muchos países, sugiere usarlo con prudencia porque también presiona en el balance de pagos. Por eso le parece ineludible que la mayor parte del esfuerzo de capitalización debe estar basado en los recursos internos de cada país, para lo cual se deben encontrar "formas de ahorro (espontáneas o de deter-

\footnotetext{
${ }^{4}$ Véase, por ejemplo, Viner (1952). Por el contrario, Furtado entendió muy bien los "límites" que Prebisch colocaba al desarrollo industrial, y no los compartía (Furtado, 1985, pag. 62). En Cattáneo (1991) se presenta un análisis de la relación que establece Prebisch entre industria y agricultura.
}

minación colectiva) que...permitan una más conveniente aplicación de los recursos a fines colectivos", entre los cuales destaca la disminución de los gastos fiscales no productivos y la reducción del consumo conspicuo de los grupos de altos ingresos. ${ }^{5}$

Finalmente, en este recuento sumario no puede dejar de mencionarse que Prebisch reconoce que sus propuestas son tentativas y es mucho lo que debe hacerse en cuanto a investigación y acción práctica para mejorar el conocimiento sobre el desarrollo latinoamericano. En la búsqueda de ese conocimiento recomienda evitar el escolasticismo, fundamentar científicamente las ideas y no aceptar las teorías elaboradas en los centros sin examinar previamente si toman en cuenta la especificidad de nuestros problemas. Por ello aconseja no "confundir el conocimiento reflexivo de lo ajeno con una sujeción mental a las ideas ajenas, de la que muy lentamente estamos aprendiendo a librarnos" (Prebisch, 1949, p. 107).

\section{Desigualdad, vulnerabilidad y patrón oro}

Se topó con el tema del desarrollo económico en el inicio de su vida intelectual, pero referido a Europa. En efecto, en 1921 comenta la Conferencia Económica Internacional realizada en Bruselas en 1920 con el fin de examinar y presentar soluciones a los grandes problemas económicos y sociales provocados por la guerra de 1914-1918, que afectaban a millones de personas de un continente entero (Prebisch, 1921a). El tema central era la "reconstrucción" económica de Europa y Prebisch sintetiza las puntos de vista de algunos de los economistas invitados, que hicieron sus diagnósticos y prescribieron las medidas a tomar. No comparte la opinión de Pantaleoni quien como "vocero del viejo evangelio económico" propone como única solución restaurar el laissez faire, y se identifica más con Gide, Bruins y Pigou - y la mayoría de los participantes - para quienes no resulta suficiente equilibrar las finanzas públicas y controlar la inflación. De nada valdrían esos esfuerzos si no se reconstruyeran y desarrollaran las fuerzas productivas mediante el mejor

\footnotetext{
5 Prebisch, 1949, p. 136 (en las citas de Prebisch los números de página corresponden a las de la compilación pertinente). A pesar del énfasis que muchos gobiernos y organismos internacionales han puesto en los últimos años en las llamadas reformas estructurales de primera y segunda generación como condiciones del desarrollo económico, un estudio reciente concluyó que los países que crecieron más rápido desde mediados del decenio de 1970 hasta finales del siglo XX fueron aquellos que invirtieron una proporción elevada de su PIB y mantuvieron la estabilidad macroeconómica (Rodrik, 1998).
} 
aprovechamiento de los factores productivos, la reducción del consumo a fin de aumentar la acumulación de capital, la remoción de las trabas al comercio, el incremento de la cooperación internacional, y la integración de los esfuerzos en el interior de cada nación para afrontar mejor estas grandes dificultades económicas, sociales y políticas. Estas propuestas tienen una notoria semejanza con las que Prebisch planteó al llegar a la CEPAL treinta años después, por lo que puede sostenerse que estuvieron rondando su pensamiento desde el principio de su evolución intelectual. Además es notorio que le cautiva el ambiente de la Conferencia, donde eminentes economistas y hombres públicos dialogan acerca de soluciones que comprometen la vida de millones de personas; es una situación en la cual le habría gustado encontrarse, como le sucedería muchas veces en años posteriores. ${ }^{6}$ Prebisch no tomó las ideas de la Conferencia como punto de partida de su pensamiento porque su interés principal estaba enfocado en la economía argentina que, en aquel entonces, no necesitaba reconstrucción ni desarrollo; al contrario, su crecimiento había sido tan exitoso que, por ejemplo, el valor de sus exportaciones se había quintuplicado en las dos primeras décadas del siglo. Dicho crecimiento, sin embargo, tenía sus problemas y Prebisch llama la atención sobre ellos, poniendo de "manifiesto" que, como se mencionó, estaba consciente de las fallas del patrón de crecimiento primario exportador, aun en una economía que, como la argentina, crecía a un ritmo elevado. Percibe dos problemas principales: la desigualdad y la vulnerabilidad externa.

Se refirió a la desigualdad económica argentina sobre todo en una exposición que realizó durante un viaje a Australia (Prebisch, 1924a). En términos muy sintéticos, afirma que los frutos del rápido crecimiento argentino basado en la exportación de productos primarios no se distribuyen de manera equitativa debido, sobre todo, a que la propiedad de la tierra está concentrada en un pequeño grupo de grandes terratenientes. Para cambiar esta situación habría que subdividir la tierra para que dejase de ser un instrumento de

\footnotetext{
${ }^{6}$ En la Conferencia se hablaba de "reconstruir" y no de "desarrollar", pero las semejanzas entre ambos conceptos son muchas, como lo hicieron notar los delegados latinoamericanos que impulsaron la creación de la CEPAL en la Asamblea de las Naciones Unidas después de la Segunda Guerra Mundial. Ellos pusieron de relieve los muchos puntos en común que existían entre la reconstrucción de Europa y el desarrollo de América Latina; si se había creado una Comisión Económica en Europa para contribuir a la reconstrucción de ese continente debía crearse otra en América Latina para ayudar a desarrollarla (véase Santa Cruz, 1995).
}

privilegio y se convirtiera en instrumento de producción eficiente en manos de una población rural amplia y desarrollada, pero los grandes terratenientes han sabido emplear su poder político para evitar cualquier acción que pudiera debilitar su situación. ${ }^{7}$

Esta situación no ha permitido el arraigo en las zonas rurales de una mayor proporción de inmigrantes extranjeros, ha favorecido la explotación extensiva de la tierra y dado lugar a una extraordinaria desigualdad entre las condiciones de vida de las clases acomodadas y las de la clase media y trabajadora. En otras palabras, la concentración de la propiedad de la tierra junto a una estructura oligárquica del poder político han servido de fundamento, junto a sus componentes externos, a un patrón primario exportador que ha permitido un ritmo elevado de crecimiento, pero ha concentrado sus frutos en pocas manos y generado una gran desigualdad económica y social. Prebisch no volvió a referirse al tema de la distribución de la tierra por muchos años y sólo retornaría a él a principios de los años sesenta (Prebisch, 1963), al mismo tiempo que José Medina Echavarría contribuía en la CEPAL con sus análisis sobre los efectos económicos, sociales y políticos de la persistencia del poder oligárquico (Medina Echavarría, 1963).

En cuanto a la vulnerabilidad externa de la economía argentina, afirma que surge del hecho elemental de que el dinamismo de las actividades primarioexportadoras requiere el impulso de la demanda externa y de los capitales externos; las fluctuaciones de estos factores provocan ciclos de crecimiento y crisis.

"En la historia monetaria argentina, a pesar de su confusa apariencia, nótase una serie de períodos de ilimitada confianza y prosperidad, de expansión en las transacciones, de especulación inmobiliaria y fantasía financiera, seguidos de colapsos más o menos intensos, precipitados en pánicos que originan la liquidación forzada de las operaciones, el relajamiento de la confianza, la postración y el estancamiento de los negocios. Sin duda, cada uno de estos ciclos no se presenta exactamente en las mismas condiciones ni con idéntico carácter pero, considerados en su conjunto, es posible encontrar en ellos hechos fundamentales que se

\footnotetext{
${ }^{7}$ En sus comentarios acerca de un proyecto de colonización del gobierno apunta que "A cada tentativa de reforma agraria en nuestro país, la agitación de ideas y el comentario de leyes extranjeras enriquecen copiosamente la literatura sobre el problema. Contrasta esta efervescencia de palabras con la acción efectiva, sofocada en un trámite legislativo poco diligente, desvanecida por la influencia de los intereses en que la gran propiedad se apuntala (Prebisch, 1924b, pág. 393).
} 
repiten, cuyo análisis permite formular síntesis acerca de su evolución. Y no es que al hacer esta afirmación, al parecer apriorística, estemos influenciados por la descripción del proceso clásico de las crisis formulado por algunos economistas. Lejos de ello, buscaremos demostrar que en nuestras crisis, aparte las diferencias de menor cuantía, interviene un factor fundamental ausente en las crisis europeas y peculiar al grado de formación histórica del país" (Prebisch, 1921d, p. 95).

Si bien la preocupación por la desigualdad sólo reaparecería muchos años después, la relativa a las fluctuaciones cíclicas lo ocupó casi por completo durante las siguientes tres décadas, hasta su entrada a la CEPAL, en que fue absorbida por el fenómeno más general del desarrollo económico. Prebisch derivó hacia el estudio histórico de las fluctuaciones cíclicas de la economía argentina debido a su interés por encontrar la causa de la depreciación de la moneda, que tenía un impacto muy negativo en los salarios reales, tema muy importante para el pensamiento socialista argentino de la época al que Prebisch estuvo vinculado. ${ }^{8}$ Estimulado por su profesor Augusto Bunge estudió las diversas propuestas mediante las cuales se pretendía estabilizar el poder adquisitivo de la moneda (Prebisch, 1921e) y criticó el enfoque de Juan B. Justo, principal líder socialista argentino de la época, quien consideraba que el factor determinante de las depreciaciones era la emisión excesiva de circulante, sin advertir el papel determinante que tienen las fluctuaciones en el balance de pagos provocadas por los mencionados factores externos (Prebisch, 1921b). ${ }^{9}$

En su análisis concreto de los varios ciclos que existieron en la economía argentina destaca la importancia de los factores externos que constituyen los elementos "objetivos" principales que impulsan en un comienzo los períodos ascendentes. En términos esquemáticos, y dando por descontada la existencia de una fuerte demanda externa, considera que es la entrada de empréstitos e inversiones externos, sobre todo des-

\footnotetext{
${ }^{8}$ El primer artículo destinado a tratar este tema parece haber sido el que publicó en el diario La Vanguardia (Prebisch, 1920). El autor agradece a José Besa el haberle facilitado una copia de dicho artículo, perteneciente a la documentación de la señora Adela Mol de Prebisch.

9 Para criticar a Justo se apoyó en la investigación de Williams (1920) sobre las fluctuaciones monetarias en Argentina, cuya lectura tuvo en él una influencia perdurable ya que le sirvió de orientación tanto por sus ideas como por el método de investigación utilizado. De todas maneras, poco después reconoció que su crítica a Justo había sido exagerada ya que las emisiones en el período analizado habían sido mayores de lo que Williams y él mismo habían afirmado (Prebisch, 1921d).
}

de 1865 en adelante, la que hace posible la convertibilidad del peso y sirve de base al aumento del circulante y el crédito que estimula la actividad económica debido a la multiplicación de oportunidades de inversión y enriquecimiento y al aumento de los gastos del gobierno, lo que culmina en una expansión "excesiva" del circulante - tanto en relación a las reservas existentes como al volumen de los negocios- que se manifiesta en un crecimiento "artificial" en que predominan la especulación privada y la irresponsabilidad fiscal. Es el momento en que los agentes económicos están dominados por un sentimiento de "confianza" en el desempeño de la economía, factor "subjetivo" de gran importancia en la aceleración de la dinámica de los ciclos. Pero el impulso productivo es sobrepasado por el especulativo, lo que trae aparejada la simiente de su propio fracaso: comienza el déficit del balance de pagos por el crecimiento desproporcionado de las importaciones y el aumento de los servicios, intereses y otras partidas del pasivo, se inicia la salida de reservas y la depreciación del peso, baja el encaje de los bancos, se restringe el crédito, se desacelera la actividad económica y se entra de lleno en el período descendente, lo que normalmente dificulta la captación de nuevos capitales externos. Los actores públicos y privados que impulsan los "excesos" monetarios y bancarios que provocan la expansión "artificial" de la economía tratan de frenar la tendencia descendente impulsando medidas como el redescuento y la inconvertibilidad; son las fuerzas sociales que defienden intereses "emisionistas" o "inflacionistas". Sin embargo, la crisis no puede contenerse y la disminución de reservas termina provocando la reducción del circulante y los créditos con la consiguiente liquidación de activos y disminución de las importaciones. Esto último hace posible obtener saldos comerciales favorables que permiten ir cancelando las deudas y reactivando la economía, lo que genera de nuevo un ambiente de confianza que atrae capitales externos, dando comienzo a un nuevo período ascendente.

Prebisch defiende en ese entonces la idea de que la liquidación de activos propiciada por la aplicación del régimen del patrón oro permite "sanear" la economía de los excesos de la expansión "artificial" y derrotar a las fuerzas emisionistas y especulativas; pero la historia económica argentina muestra que es una derrota transitoria ya que volverán a aparecer en el próximo período ascendente. Por supuesto, la entrada de capitales externos depende tanto de su disponibilidad como de las expectativas de confianza y rentabilidad que los inversores perciban en el país prestatario. 
Prebisch nota que ha habido ocasiones en que la abundancia de capitales en los países prestadores y el predominio en ellos de un sentimiento de confianza le permitió algunas veces a Argentina seguir captando capitales y postergar el comienzo del período descendente pese a la existencia de déficit apreciables en su balance comercial; sin embargo, tales postergaciones nunca lograron evitar que finalmente se produjera la crisis.

Pese a que hemos mostrado aquí la visión cíclica de Prebisch en forma extremadamente esquemática, es posible advertir la significación que ella tiene para las ideas que presentó en 1949.

Ante todo, como él mismo reconoció, dicha visión cíclica es el origen de su convicción de que el patrón primario-exportador es intrínsecamente vulnerable a las variaciones en la demanda externa y el flujo de capitales, que se constituyen así en un elemento explicativo principal de las fluctuaciones económicas. En otras palabras, afirma que la economía argentina ha establecido una relación con los países industriales en la que su funcionamiento depende de la demanda y de los capitales de estos países, lo que trajo aparejado un considerable crecimiento, pero sujeto a fluctuaciones que no se han logrado controlar. La visión esquemática de Prebisch es dicotómica: por un lado están los países industriales y acreedores y, por otro, Argentina, país primario exportador y deudor. Entre ambos existe una diferencia de grado de "formación histórica" que equivale no tanto a desigualdad en condiciones de vida, sino a solidez social e institucional; al menos es lo que trasunta la comparación que establece entre los bancos argentinos y el Banco de Inglaterra. El concepto que más se le asemeja es el de desarrollo-subdesarrollo, si se lo entiende de una manera que abarque no sólo dimensiones económicas. Pero, además, entre los miembros de aquella dicotomía no existe sólo una gradación, en el sentido de que tienen grados desiguales de formación histórica, sino también una relación funcional en cuanto desempeñan funciones y mantienen relaciones de interdependencia dentro de una misma estructura y, aun más, dicha relación funcional implica una relación de dominación en la estructura constituida por el mercado mundial. ${ }^{10}$

Definitivamente, a Prebisch no le agrada que Argentina esté inserta en una estructura en la cual obtiene beneficios pero que acarrea pérdida de control.

\footnotetext{
${ }^{10}$ Este último aspecto se refiere a lo que Max Weber denomina "dominación basada en una constelación de intereses", que debe ser diferenciada de la dominación basada en la autoridad (Weber, 1964, vol. II)
}

Resulta evidente que desde esta visión al esquema centro-periferia hay un paso; basta que generalice su enfoque a todos los países primario-exportadores y deudores. Como se recordará, la vulnerabilidad externa es uno de los defectos que le atribuye en el Informe de 1949 al patrón primario exportador, aunque en esa oportunidad prestó mayor atención a la vulnerabilidad comercial que a la financiera porque en ese momento era muy escaso el acceso de los países latinoamericanos a los capitales internacionales después de las cesaciones de pago posteriores a la crisis. En las últimas décadas, la vulnerabilidad financiera asociada a la condición de país deudor ha recobrado toda su importancia en América Latina.

En segundo lugar, Prebisch puso mucho énfasis en sus trabajos iniciales en la importancia que tenían los factores externos en el dinamismo cíclico argentino porque percibió que no se les otorgaba la importancia debida en relación a los internos. Pero ello no significa que haya ignorado estos últimos; por el contrario, su perspectiva de análisis es mucho más compleja que la implicada en una mera dependencia de los estímulos del exterior ya que incorpora elementos internos sociológicos y sicosociales. Tanto los sentimientos predominantes en los actores, en especial la mayor o menor confianza que depositen en las perspectivas económicas, como las "fuerzas sociales" desempeñan un papel significativo en la dinámica de los ciclos. ${ }^{11}$

A su juicio, el enfoque más adecuado para estudiar los ciclos es semejante al que los sociólogos de CEPAL propondrían cuarenta años después para estudiar el proceso histórico del desarrollo en América Latina: prestar mucha atención a los factores externos pero estar consciente que su impacto en la sociedad periférica no se manifiesta de manera directa, ya que es mediatizado por las actitudes y comportamientos de las fuerzas sociales internas. Prebisch resume su visión señalando que la dinámica económica es consecuencia de una "serie de acciones y reacciones mutuas entre ambas categorías de factores" (Prebisch, 1921d). Sin embargo, aunque aprecia la relevancia de los factores internos lamenta no poder estudiarlos, quizá por sentirse sin los conocimientos sociológicos para hacerlo; aparentemente, dicho estudio tampoco lo hizo ningún sociólogo de la época, perdiéndose la oportunidad de

\footnotetext{
${ }^{11}$ La incorporación de factores subjetivos en el análisis de los ciclos muestra la influencia de Pareto. Para este autor, los fenómenos sociales se manifiestan como fluctuaciones cíclicas y en ellas los sentimientos de los actores — base de las acciones no lógicasdesempeñan un papel decisivo (véase Prebisch, 1923b).
} 
sentar las bases de una teoría sociológica de los ciclos económicos argentinos. ${ }^{12}$

En tercer lugar, de manera paradójica, en aquellos años Prebisch combina su visión crítica del patrón primario-exportador con la convicción de que las reglas del patrón oro permiten "sanear" a la economía de los excesos monetarios y fiscales y de los desajustes del sector externo, constituyéndose así en el mecanismo idóneo para recuperar el equilibrio macroeconómico, disciplinar a las fuerzas sociales y retomar el crecimiento. Esta es la dimensión ortodoxa que permanece en su pensamiento y sólo se desmoronará con la crisis de 1929, aunque existen indicios de que antes de esa fecha ya había comenzado a dudar de la misma. Su confianza en el patrón oro lo lleva a rechazar las iniciativas de creación de cualquier institución que tuviera por finalidad la regulación del ciclo económico. Califica de "ortopedia bancaria" la idea de Norberto Piñero de crear un banco que regule los ciclos (Prebisch, 1921c) y, del mismo modo, critica a Emilio Frers quien propone la creación de una Caja Internacional de Convertibilidad. "Todos los países de moneda envilecida aspiran a llegar de nuevo al patrón oro. ¿A qué entonces manosearle? Y algunos de ellos por una drástica desinflación del circulante, por la economía en los gastos públicos y el esfuerzo tenaz en mejorar sus balances de pagos internacionales están a punto de conseguirlo. Tal es el caso de la Gran Bretaña. Y economistas de nota ya lo señalan como ejemplo" (Prebisch, 1923a, p. 359).

Lo paradójico es que al mismo tiempo que llamaba la atención sobre la importancia de los factores externos en la dinámica de los ciclos aceptaba que la política económica se basase en un mecanismo que responsabiliza a los factores internos de los desequilibrios externos. De todos modos, Prebisch cree que la política de "liquidación" necesaria para recuperar el orden después de los "excesos" debiera ser utilizada para evitar que los mismos se repitan, reorientando la economía hacia un crecimiento más genuino. Tal cosa significa que las actividades productivas y financieras se basen de manera preferente en el ahorro interno - el externo es fuente de vulnerabilidad e inestabilidad porque siempre termina yéndose- y el circulante y los

\footnotetext{
${ }^{12}$ En los trabajos de la CEPAL este vacío fue cubierto transitoriamente durante la década de 1960 debido a la contribución de varios sociólogos, entre los que destacaron José Medina Echavarría y Fernando Henrique Cardoso. Desde los años setenta esta línea de análisis ha sido interrumpida en la CEPAL debido a la prevalencia de un enfoque economicista.
}

créditos se adecuen a las reservas existentes y a las necesidades reales de la economía. En otras palabras, anhela una economía más productiva y menos especulativa, con una solidez ganada desde adentro sobre la base de ahorro e inversión internos, menos espasmódica en su crecimiento, con una moneda sana y bancos consolidados. Nada dice acerca de cambios en el patrón de desarrollo y no menciona la industrialización, pero puede presumirse que debe haber pensado en ello pues ¿de qué otro modo podría elevar Argentina su grado de "formación histórica" y reducir la vulnerabilidad externa?

Finalmente, es muy probable que la escasa atención que los economistas de Argentina le dedicaban en aquel entonces a los factores externos en la evolución de los ciclos argentinos, siguiendo las ideas predominantes en los centros, le haya mostrado a Prebisch por primera vez y con mucha claridad el peligro de aceptar a priori teorías que fueron elaboradas en otros contextos, dejando de lado las especificidades de la situación argentina, recomendación que reiterará en 1949. Tal como se mencionó, ello no significa que proponga ignorar esos esfuerzos teóricos; por el contrario, habría que extraer de ellos todo su valor, como él mismo lo hizo con las investigaciones del economista de Harvard, John Williams, que le mostraron la importancia que debe dárseles a los factores externos en los ciclos argentinos. Al respecto, advierte que la subestimación de estos factores ha provocado errores de política de gran significación aun en los centros, como ha sucedido con las recomendaciones internacionales que se le hicieron al gobierno alemán de la época para enfrentar sus graves problemas monetarios. Basadas en el enfoque clásico, dichas recomendaciones insisten en que esos problemas son causados por el aumento del circulante, el que a toda costa debiera ser reducido, sin advertir que tal expansión es provocada por las exigencias de las reparaciones de guerra. Prebisch concluye que es inútil insistirle al gobierno alemán que controle la expansión monetaria si antes no se llega a un acuerdo internacional que le alivie el peso de las reparaciones (Prebisch, 1922a).

\section{Crisis y consolidación del enfoque heterodoxo}

Las ideas que acaban de presentarse las formula entre 1921 y 1924. En los años siguientes sigue muy interesado en el estudio de los problemas cíclicos de la economía argentina, pero se enfrenta con la falta de información empírica, por lo que dedica un gran esfuerzo a la elaboración y recopilación de estadísticas que 
le permitan profundizar su análisis. Se hace cargo primero de la Subdirección del Instituto de Estadística Nacional, luego de la Oficina de Estadística de la Sociedad Rural y, a partir de 1927, de la Oficina de Investigaciones e Información del Banco de la Nación Argentina. La información recopilada le sirve de base - sobre todo en el último cargo - para llevar a cabo descripciones pormenorizadas de la coyuntura económica; su enfoque sigue siendo el que había desarrollado en los años anteriores, pero, como es de esperar en un autor que trabaja en una oficina gubernamental, reduce la crítica y aumenta la descripción empírica.

Estos estudios reflejan su esfuerzo por desentrañar el significado de las tendencias recesivas que percibe desde 1928. Los primeros síntomas de lo que a la postre se transformaría en la gran crisis de 1929 le permiten poner de relieve que, otra vez, Argentina -en tanto país que depende de la demanda y de los capitales externos- está siendo afectada por las turbulencias originadas en las principales economías industriales. A mediados de 1928 comienza a disminuir la entrada de capitales externos debido al alza de las tasas de interés por la Reserva Federal, muy preocupada por la expansión del crédito dedicado a la especulación bursátil y, además, caen los precios de los productos exportados por Argentina debido a la disminución de la demanda de los países industriales. Ello obliga al gobierno argentino a saldar su creciente déficit de balance de pagos mediante la salida de metálico, con sus consecuencias sobre el proceso monetario (Prebisch, 1929 y 1930a). Pero en dichos estudios también advierte - primera vez que menciona el fenómeno-que la caída de los precios agropecuarios se ve agravada porque los precios de los productos agropecuarios caen más que los de los productos industriales. Este proceso de deterioro relativo de los precios de los bienes primarios en relación con los industriales respondería a causas diversas, pero en esa ocasión sólo argumenta que estaría causado porque la inelasticidad de la oferta agropecuaria no ha permitido que ésta acompañe la caída de la demanda externa.

Hasta mediados de 1930 (Prebisch, 1930a y 1930b) sostiene que estos fenómenos son nada más que las manifestaciones propias de otro descenso cíclico, de los muchos que ha tenido Argentina. "Trátase de un fenómeno de coyuntura económica, de un período de descenso en el movimiento ondulatorio que caracteriza normalmente la evolución de cualquier país; de un hecho meramente superficial...que por sí mismo no afecta la estructura de la economía nacional ni comporta desvío significativo en la dirección persistente de ascenso de sus actividades económicas" (Prebisch, 1930a, pp. 613-619).

En estas circunstancias, comienza una nueva etapa en la vida de Prebisch porque en 1931 asume como subsecretario de Hacienda y se ve obligado a contribuir de manera decisiva en la tarea de formular y aplicar políticas para enfrentar la crisis. Durante ese año y el siguiente la política del gobierno combina medidas ortodoxas, como disminución del gasto público, aumento de impuestos y disminución del crédito, con otras de naturaleza heterodoxa como autorizar la realización de operaciones de redescuento a fin de mejorar la situación de los bancos y sus acreedores (Prebisch, 1931a), elevar los aranceles para contrarrestar el desequilibrio del balance de pagos y reducir el déficit fiscal, controlar el cambio para defender el valor del peso en relación al oro (Prebisch, 1931b) e introducir el impuesto a la renta para mejorar la recaudación fiscal (Prebisch, 1932a). Estas medidas heterodoxas que Prebisch ayudó a formular y poner en marcha a partir de 1931 fueron siempre presentadas como transitorias y extraordinarias de modo que fueron aceptadas por el resto de los miembros del gobierno y por la élite económica, donde predominaba la tendencia ortodoxa en política económica. Siempre fueron presentadas como la imposición de una realidad que se había trastocado; cuando volviera la normalidad ellas serían abandonadas y se retornaría a la "buena doctrina". A ellas debe agregarse un proyecto de creación de un Banco Central que Prebisch redactó en 1931 - y el Ejecutivo no se animó a presentar al Congreso temiendo que lo considerase demasiado intervencionista y permanente - donde proponía regular no sólo las tendencias inflacionarias en la creciente de los ciclos sino también - heterodoxia inaceptable - las recesivas en la menguante (Prebisch, 1972).

Por lo tanto, con mucha rapidez abandona el patrón oro y se vuelca a la heterodoxia, cuando todavía creía que la crisis era sólo una declinación cíclica; ya no acepta que la "liquidación" de activos sea un recurso aceptable para salir de la crisis y que deba darse plena libertad de acción a los mecanismos automáticos del mercado. La rapidez de ese cambio de ideas hace sospechar que ya antes de la crisis había comenzado a dudar de tales convicciones; en efecto, de manera explícita ya había expresado sus dudas acerca de la eficacia de los mecanismos de mercado cuando, años antes de la crisis, apoyó la intervención estatal en el mercado de la carne (Prebisch, 1927). Asimismo, en el proyecto de autorización del redescuento en 1931 y de manera muy enfática en 1932 rechaza el mecanis- 
mo de "liquidación" de activos para sanear la economía y recobrar el crecimiento; el Estado no puede ser liquidado y no ve ninguna ventaja en liquidar al productor rural que no puede pagar sus créditos por la disminución de los precios internacionales de sus productos.

En los escritos de esos años recupera su antigua idea de que en la dinámica de los ciclos intervienen factores externos e internos; así afirma que los problemas que está padeciendo Argentina derivan tanto de los excesos monetarios y fiscales como de las dificultades externas que provienen de la caída de los precios de los productos de exportación y la merma en la entrada de capitales, y también de la débil institucionalidad monetaria. Por ello que su propuesta a mediados de 1932 es atacar todos esos factores al mismo tiempo mediante medidas restrictivas monetarias y fiscales, control de cambios y del comercio exterior, y de un Banco Central que ordene la institucionalidad y la política monetaria y regule las fluctuaciones cíclicas. En ese momento todavía afirma que la crisis es sólo un descenso cíclico, pero intuye algo peor: la evolución económica argentina desde hace muchas décadas ha sido de un "crecimiento apenas interrumpido por depresiones cuya escasa duración y amplitud contrastan con los rasgos acentuados del presente receso" (Prebisch, 1932b, p. 86).

Pero en 1933 ya no le quedan dudas de que la crisis no es un mero descenso cíclico: entre 1929 y 1933 los precios de los productos agropecuarios se redujeron casi a la mitad en pesos y a menos de una tercera parte en oro; de hecho, los precios en oro en 1933 eran bastante inferiores a los existentes en 1900. Esta disminución es de una magnitud y duración mucho mayores que las producidas en los descensos cíclicos y, en consecuencia, su impacto es más amplio y profundo, hasta el punto de "...trastornar violentamente la estructura económica del país”. (Prebisch, 1933c, p. 135). Debido a ello, para pagar una misma suma de intereses de su deuda Argentina debe disponer en 1933 de 200\% más de productos agropecuarios que en 1929 $\mathrm{y}$, debido al deterioro de los precios de los productos agropecuarios en relación con los industriales, para comprar la misma cantidad de éstos Argentina debe pagar en 1933 un 78\% más de aquellos que en 1929.

Este grave diagnóstico va unido a un pronóstico pesimista acerca de la posibilidad de retornar a corto plazo a la situación anterior a la crisis. Dos sucesos deben haberlo influido mucho en esta apreciación. Por un lado, al participar en la organización de la Conferencia Económica Mundial en 1932/1933 percibe las enormes dificultades políticas, comerciales y financieras que entraban la economía internacional; entre otras, la persistencia de los problemas vinculados a las deudas de guerra, los obstáculos para que se reduzcan los aranceles, el dislocamiento de los tipos de cambio y la política proteccionista y de acumulación de reservas seguida por los Estados Unidos. Este último tema, que aparecerá muy destacado en Prebisch (1949), le preocupa en especial dada la posición central de ese país en la economía internacional. Algunos de estos problemas ya existían antes de 1929 - como las deudas de guerra y las tendencias proteccionistas-, pero la crisis los agrava a la vez que crea otros nuevos (Prebisch, 1933a). Dicho pesimismo debe haber sido reforzado por las condiciones que Argentina tuvo que aceptar en las negociaciones con Gran Bretaña, que se concretaron en el pacto Roca-Runciman de 1933. Prebisch formó parte del equipo negociador argentino y conoció de primera mano la fuerza con que Gran Bretaña, principal comprador de los productos argentinos, hacía valer su poder económico para regular el intercambio con Argentina de acuerdo a sus intereses (Prebisch, 1933b). ${ }^{13}$

En tales circunstancias, deben haber confluido tres ideas en la mente de Prebisch: i) la plena ratificación de su antigua crítica a la vulnerabilidad externa de la economía argentina en tanto país agrario-exportador y deudor, unida a la más reciente idea del deterioro; ii) la convicción de que la crisis era mucho más amplia y profunda que un descenso cíclico y que trastocaba la estructura misma de la economía, y iii) la escasa probabilidad que tenía Argentina de retornar a la situación anterior a la crisis debido a los problemas existentes en la economía internacional, tanto a nivel multilateral como bilateral. Tales ideas deben haberlo convencido de que era necesario profundizar su búsqueda de nuevos caminos que permitieran sacar a su país de la situación en que se encontraba.

Ya se había convencido de que los mecanismos automáticos del patrón oro no eran apropiados a la situación argentina porque eran procíclicos y atacaban el desequilibrio externo de manera indirecta, mediante medidas restrictivas fiscales y monetarias, lo que provocaba un costo económico y social que le resultaba inaceptable; dicho desequilibrio debía ser buscado con medidas directas, orientadas a regular el mercado

\footnotetext{
${ }^{13}$ El artículo citado de González y Pollock examina muy bien la influencia de estos eventos en el pensamiento - y el ánimo- de Prebisch.
} 
de cambios y el comercio exterior. Constituía un avance en su heterodoxia, pero sólo se refería a la manera -intervencionista y no automática- de lograr el equilibrio de las cuentas externas. Pero le faltaba dar un paso adicional y decisivo referido a la aplicación de políticas activas para sacar a la economía argentina de la recesión, y decidir en qué medida eso requeriría el establecimiento de un nuevo patrón de desarrollo, ahora que estaba consciente de que el primario-exportador no desempeñaría, al menos por un tiempo prolongado, el papel dinámico que había tenido antes de la crisis. En ese aspecto, Prebisch recibió la influencia tanto de las ideas que se estaban formulando en esos años en los países industriales —donde resalta la contribución de Keynes- como de las políticas que se aplicaban en ellos, en especial en Gran Bretaña y Estados Unidos. Pero el análisis de ese tema queda fuera de los límites de este artículo. ${ }^{14}$

Ese paso comienza a darlo en el Plan de Acción Económica Nacional que elabora junto a varios colaboradores a fines de 1933 con el fin explícito de "aliviar al país del peso de la depresión económica" (Prebisch, 1934a, p. 146). Habiendo ordenado la situación monetaria y fiscal, el Plan destina un primer conjunto de medidas a atacar el desequilibrio del balance de pagos, que padece Argentina en tanto país agrarioexportador y deudor, mediante la devaluación y el control del cambio y las importaciones. En la defensa de tales medidas rompe lanzas de manera explícita y definitiva con el esquema del patrón oro ya que el mismo sólo sirve para equilibrar alteraciones de los precios y del balance de pagos que han sido provocadas por un aumento excesivo del circulante, pero en 1933 nadie puede poner en duda que dichas alteraciones no han sido causadas por "excesos" o fallas de cálculo de los agentes económicos, sino por una caída de los precios internacionales de una magnitud inusitada e imprevisible. Aplicar el mecanismo del patrón oro, ignorando la importancia causal de los factores externos, ahondará la crisis al provocar una descomunal liquidación de activos. ${ }^{15}$ Estas ideas ya las había formulado con anterioridad pero en este Plan resalta que, además de buscar el equilibrio del sector externo, dichas medidas tienen el objetivo adicional de reactivar la economía; el control de cambios y de las importaciones protegerán a la actividades industriales

\footnotetext{
14 Al respecto pueden consultarse los artículos de Love (1994 y 1999), González y Pollock (1991) y Rodríguez (2001a y 2001b).

$15 \mathrm{Su}$ crítica del patrón oro aparece en varios trabajos de la época. Véase en especial Prebisch (1934c).
}

internas de la competencia externa y la devaluación tendrá un efecto beneficioso en los productores rurales. Si no se hubiese devaluado, los precios internos de los productos agrícolas caerían a la par de los internacionales y los productores no podrían pagar sus deudas contraídas en un nivel de precios superior, provocando una liquidación en cadena de activos de enorme magnitud; la devaluación atenuará el impacto de la disminución de los precios internacionales sobre dichos productores.

Un segundo conjunto de medidas está destinado a impulsar la reactivación de la producción industrial de manera directa mediante la recuperación de la demanda interna. Argumenta que la disminución del poder de compra de la población ha contraído la actividad económica y aumentado la desocupación, llegándose a una situación que debe ser destrabada por el gobierno mediante un gran plan de obras públicas que disminuya la desocupación y aumente el poder adquisitivo y el consumo de la población, estimulando la reactivación de la producción industrial interna, adicionalmente protegida por la incapacidad para importar. Advierte que en los años recientes la protección brindada por los aranceles y el mayor costo de las divisas han favorecido el consumo y la producción internos, dando lugar a un proceso de gran trascendencia: "las industrias locales...han logrado ensanchar su producción mientras declinaba el comercio exterior" (Prebisch, 1934b, p. 201). En suma, “...difícilmente podrá venir de afuera el estímulo que requiere imperiosamente la economía argentina, hay que buscar las soluciones dentro del país mismo" (Ibid., p. 144).

El Plan presenta muchos otros aspectos dignos de interés como, por ejemplo, la atención que presta a los efectos redistributivos de las medidas de política económica en los diferentes grupos sociales, como ya lo había insinuado en sus estudios juveniles. A su vez, este tema es la puerta de entrada a otro de gran importancia, que es el de las consecuencias sociales de las políticas económicas. En efecto, cuando los efectos redistributivos son causados por la mano invisible del mercado, como en el régimen de patrón oro, el economista no se ve obligado a tomar decisiones éticas complicadas; pero cuando los provoca con su intervención no puede dejar de tomarlos en cuenta y examinarlos con cuidado. Por ejemplo, la devaluación favorece a los productores rurales al mejorar los precios internos de sus productos, lo que a Prebisch le parece justo porque ha sido uno de los grupos más perjudicados por la crisis. Pero eso puede estimular a algunos de ellos a vender su producción en el exterior a precios de remate perjudicando al resto, por lo que el Gobierno lo impi- 
de creando una institución para controlar ese proceso (la Junta Nacional de Granos). U otros productores pueden pretender beneficiarse en exceso vendiendo las divisas obtenidas en el mercado negro, por lo que el Gobierno los obliga a cambiarlas en el mercado oficial. Esto pone en evidencia que el Plan no sólo es importante por su heterodoxia y su carácter expansivo, sino también por su preocupación por los efectos distributivos de las medidas tomadas.

¿En qué medida este Plan pretende reorientar la actividad económica hacia un patrón de desarrollo en que el desarrollo industrial juegue un papel decisivo o sólo está preocupado por estimular la actividad económica? Si se toma en cuenta lo dicho acerca de la evolución anterior de sus ideas no cabe duda que este Plan es la primera respuesta de Prebisch al interrogante de cómo Argentina podía dejar de ser un país agroexportador y deudor; interrogante que Prebisch debe haberse planteado desde el momento inicial de su vida intelectual, cuando percibió los problemas que esas características traían aparejadas. En aquellos años había señalado que la condición de país deudor podía superarse mediante un gran esfuerzo de ahorro interno, pero hasta 1933 nada había escrito acerca de cómo hacer lo mismo con la de país agro-exportador. Sin embargo, la idea de la industrialización debe haber rondado su mente porque ¿de qué otro modo Argentina podía superar aquella condición y elevar su "grado de formación histórica" hasta asemejarse a los países importantes del mundo? Pero resultaría difícil defenderla mientras Argentina obtuviese una elevada tasa de crecimiento como país agro-exportador y el poder económico estuviese en manos de una élite cuyo núcleo estaba formado por los propietarios de la tierra. Pero la situación cambia en 1933 cuando es evidente que las actividades agro-exportadoras han entrado en una crisis profunda debido a la severa caída de los precios de exportación y el deterioro de la relación de precios del intercambio, el dislocamiento del comercio internacional a consecuencia de la crisis y el proteccionismo de los Estados Unidos, y la industrialización exhibe su capacidad para aumentar la oferta de bienes y mejorar la ocupación y el ingreso.

Finalmente, cabe hacer algunas apreciaciones acerca de la visión que Prebisch tenía en sus años juveniles acerca de la intervención estatal en la economía, tema que nunca trató de manera explícita. ${ }^{16}$ Ante todo, Prebisch era - y siempre fue - un ferviente

16 Sobre la concepción del Estado en el pensamiento de la CEPAL puede consultarse Gurrieri, 1987. defensor de un proceso económico disciplinado y austero, rechazando todos los "excesos", fueran monetarios, fiscales, de comercio exterior, de consumo u otros. Esa actitud está presente desde el inicio de su vida personal e intelectual y es la causa de que siempre creyera en la virtud de tener las cuentas ordenadas, evitar el consumo conspicuo y basar el crecimiento en el ahorro interno sin recurrir a los recursos fáciles, pero espurios, del endeudamiento externo y la inflación. En principio creyó que el libre juego de las fuerzas del mercado sería suficiente para lograrlo, pero cuando entre fines de los veinte y principios de los treinta se fue dando cuenta de que ése no era el camino propició la intervención estatal. No le cabía duda de que había que orientar y disciplinar a los actores económicos privados; por ejemplo, trata con desprecio a los terratenientes que no son capaces de darse cuenta de sus verdaderos intereses ${ }^{17} \mathrm{y}$ en el decreto en que fundamenta el control de cambios argumenta sin ambages que "es necesario sustituir a la anarquía dañosa que impera en el mercado por un método centralizado y dirigido por los más capacitados" (Prebisch, 1931b, p. 4). Cada vez más le resulta evidente que el proceso económico debe ser regulado por una élite estatal esclarecida que logre evitar las presiones de los agentes económicos poderosos y también las de los gobiernos quienes, como lo mostró en sus análisis iniciales sobre los ciclos, suelen manejar sus asuntos económicos de una manera imprevisora, electoralista y, a menudo, corrupta.

\section{Conclusiones}

El pensamiento de Prebisch sobre el desarrollo comienza en 1921, cuando toma conciencia de que la economía argentina es muy vulnerable a las fluctuaciones que provienen de los países industriales debido a la posición que ocupa en el sistema económico mundial. Esa es la piedra fundamental del edificio teórico que fue construyendo a lo largo de los años y tomó forma definitiva en el esquema centro-periferia. El exponente más importante del pensamiento estructuralista latinoamericano no necesitó experimentar el impacto de la crisis de 1929 para advertir el carácter intrínsecamente vulnerable y desigual de un patrón de crecimiento cuyo funcionamiento depende de la demanda y los capitales

\footnotetext{
17 “... la crisis ganadera ha turbado el letargo de los hacendados argentinos, y tal vez contribuya poderosamente a que su instinto de clase - incoherente, desorientado y negativo las más de las vecesse transforme en clara conciencia de sus intereses económicos" (Prebisch, 1922b, p. 349).
} 
externos y se basa en la concentración de la propiedad de la tierra; la crisis confirmó su diagnóstico y le impuso la tarea de buscar soluciones, pero no fue la causa que los originó. Por lo tanto existe una notoria continuidad en la evolución de las ideas de Prebisch desde sus primeros escritos juveniles hasta el Informe de 1949 en que presenta su "manifiesto" desarrollista; en aquellos escritos se encuentran, en mayor o menor grado, casi todas las ideas que presentó al incorporarse a la CEPAL, por lo que resulta equivocado dejarlos de lado como si fuesen mera expresión de pensamiento neoclásico.

Desde 1921 le queda planteada a Prebisch la pregunta acerca de cuál sería una manera menos vulnerable y desigual de organizar las actividades económicas en la Argentina. Con respecto a la dependencia del capital externo su respuesta fue inmediata: debe ponerse un énfasis mucho mayor en el ahorro interno. La respuesta a la dependencia de la demanda externa y de la desigualdad eran mucho más complicadas porque implicaban una reestructuración profunda de la economía y chocaban de frente con los intereses dominantes. Como se mencionó, al tema de la desigualdad basada en la concentración de la propiedad sólo volvió a principios de los sesenta, pero una primera respuesta al relativo a la demanda externa ya la dio en el Plan de 1933, aunque es probable que haya rondado su mente desde mucho antes. Lo que puede decirse sobre la base de sus escritos es que en la búsqueda de nuevos caminos para aminorar la vulnerabilidad externa tuvo que deshacerse, ante todo, de su adhesión al patrón oro. Tal cosa sucedió cuando se convenció de que dicho patrón era inadecuado porque sometía las políticas monetaria y cambiaria a un criterio ciego a los intereses de la economía argentina dado que expandía, en vez de reducir, las fluctuaciones cíclicas y llevaba a aplicar medidas fiscales y monetarias restrictivas que generaban un alto costo social. Es entonces que propone la intervención directa sobre la tasa de cambio y el comercio exterior, y comienza a aplicar medidas en ese sentido cuando asume una posición de gobierno en 1931. Pero esas medidas, además de contribuir al equilibrio del balance de pagos, ayudan a reactivar la economía porque alientan la producción interna con efectos beneficiosos sobre la ocupación y el ingreso. O sea, le demuestran, si es que necesitaba tal demostración, que la industrialización debía ser un componente esencial de la respuesta acerca de cómo reducir la dependencia de la demanda externa; por lo que a fines de 1933 contribuye a redactar un Plan que combina medidas de control del sector externo con otras orientadas de manera expresa a estimular la demanda y la oferta internas. Esa es su primera respuesta consistente acerca de cómo modificar la situación de vulnerabilidad estructural en que se encontraba la economía argentina. Pero el propio desarrollo industrial de esos años le permite advertir que la industrialización trae aparejada su propia vulnerabilidad externa, por lo que insiste en la necesidad de compatibilizar dicho desarrollo con la expansión de las exportaciones, tema al que presta mucha atención en el Informe de 1949.

Muchas otras ideas presentadas en ese Informe ya están presentes en sus escritos juveniles: el agravamiento de la vulnerabilidad externa por el deterioro de la relación de precios del intercambio; las dificultades que provoca la política proteccionista seguida por Estados Unidos; y el error de aceptar a fardo cerrado los diagnósticos y propuestas elaborados en los países industriales porque pueden referirse a una realidad diferente, lo que obliga a los economistas a ejercitar un grado considerable de creación independiente y juicio crítico si quieren entender y enfrentar con éxito los problemas de sus realidades nacionales. También estaba convencido en su juventud que se requería una combinación de mercado e intervención estatal para reorientar la economía en el sentido deseado e impulsar su crecimiento. Desconfiado de las élites políticas, pensó que dicha intervención debía ser llevada a cabo desde una institución con gran autonomía, que cobijara a técnicos capaces de disciplinar y orientar a los agentes privados y públicos de acuerdo a una racionalidad técnica y sustantiva dirigida en beneficio de la colectividad en su conjunto. Tal idea expresa de manera cabal la forma en que entonces concebía el papel de los técnicos en el proceso decisorio y así lo estableció en la CEPAL y, por cierto, en el Banco Central de la Argentina, que contribuyó a crear y cuya gerencia general asumió en 1935. 
Cattáneo, C. (1991): Prebisch y las relaciones agricultura-industria, Revista de la Cepal, $\mathrm{N}^{\circ}$ 43, LC/G.1654-P, Santiago de Chile, CEPAL.

Furtado, C. (1985): A fantasia organizada, Rio de Janeiro, Paz e Terra.

González, N. y D. Pollock (1991): Del ortodoxo al conservador ilustrado. Raúl Prebisch en la Argentina 1923-1943, Desarrollo económico, vol. 30, No 120, Buenos Aires, Instituto de Desarrollo Económico y Social (IDES).

Gurrieri, A. (1987): Vigencia del Estado planificador en la crisis actual, Revista de la CEPAL, $\mathrm{N}^{\circ} 31, \mathrm{LC} / \mathrm{G} .1452$, Santiago de Chile, CEPAL.

Love, J. (1994): Economic ideas and ideologies in Latin America since 1930, The Cambridge History of Latin America, Cambridge, Massachusetts, Cambridge University Press.

(1999): Las fuentes del estructuralismo latinoamericano, J. Lora y C. Mallorquín (comps.), Prebisch y Furtado. El estructuralismo latinoamericano, México, D.F., Universidad Autónoma de Puebla.

Medina Echavarría, J. (1963): Consideraciones sociológicas sobre el desarrollo económico, Buenos Aires, Solar-Hachette.

Prebisch, R. (1920): ¿Salarios a oro?, La Vanguardia, Buenos Aires. (1921a): La conferencia de Bruselas, Revista de Ciencias Económicas, vol. 9, $\mathrm{N}^{\circ} 1$, Buenos Aires. Reproducido en Raúl Prebisch. Obras 1919-1948, vol. I, Buenos Aires, Fundación Raúl Prebisch, 1991.

(1921b): Estudios sobre la moneda. J. B. Justo, Revista de ciencias económicas, vol. $9, \mathrm{~N}^{\circ} 2$, Buenos Aires. Reproducido en Raúl Prebisch. Obras 1919-1948, vol. I, Buenos Aires, Fundación Raúl Prebisch, 1991.

(1921c): La ortopedia bancaria del Profesor Piñero, Revista de ciencias económicas, vol. 9, $\mathrm{N}^{\circ} 2$, Buenos Aires. Reproducido en Raúl Prebisch. Obras 1919-1948, vol. I, Buenos Aires, Fundación Raúl Prebisch, 1991.

(1921d): Anotaciones sobre nuestro medio circulante. A propósito del último libro del doctor Norberto Piñero, Revista de ciencias económicas, $\mathrm{N}^{\text {os }}$ 4-6-7-10-11, Buenos Aires. Reproducido en Raúl Prebisch. Obras 1919-1948, vol. I, Buenos Aires, Fundación Raúl Prebisch, 1991.

(1921e): Planes para estabilizar el poder adquisitivo de la moneda, Investigaciones de seminario, Buenos Aires, Universidad de Buenos Aires. Reproducido en Raúl Prebisch. Obras 1919-1948, vol. I, Buenos Aires, Fundación Raúl Prebisch, 1991.

(1922a): Sobre la degradación del marco y el pago de las reparaciones, Revista de ciencias económicas, vol. 10, $\mathrm{N}^{\circ} 12$, Buenos Aires. Reproducido en Raúl Prebisch. Obras 19191948, vol. I, Buenos Aires, Fundación Raúl Prebisch, 1991. (1922b): Anotaciones sobre la crisis ganadera, Revista de ciencias económicas, vol. 10, $\mathrm{N}^{\circ} 17$, Buenos Aires. Reproducido en Raúl Prebisch. Obras 1919-1948, vol. I, Buenos Aires, Fundación Raúl Prebisch, 1991.

(1923a): La Caja Internacional de Conversión, Revista de ciencias económicas, vol. 11, $\mathrm{N}^{\circ} 18-19$, Buenos Aires. Reproducido en Raúl Prebisch. Obras 1919-1948, vol. I, Buenos Aires, Fundación Raúl Prebisch, 1991.

(1923b): La sociología de Vilfredo Pareto, Revista de ciencias económicas, vol. 11, $\mathrm{N}^{\circ} 27$, Buenos Aires. Reproducido en Raúl Prebisch. Obras 1919-1948, vol. I, Buenos Aires, Fundación Raúl Prebisch, 1991.

(1924a): El problema de la tierra, Conferencia dictada y publicada en Australia. Reproducido en Raúl Prebisch. Obras 1919-1948, vol. I, Buenos Aires, Fundación Raúl Prebisch, 1991. (1924b): Aclaraciones al Proyecto de Colonización del Poder Ejecutivo, Revista de economía argentina, vol. 13, $\mathrm{N}^{\circ}$ 75-76, Buenos Aires, septiembre-octubre.

(1927): El régimen de pool en el comercio de carnes, Revista de ciencias económicas, vol. 15, № 77, Buenos Aires. Reproducido en Raúl Prebisch. Obras 1919-1948, vol. I, Buenos Aires, Fundación Raúl Prebisch, 1991.

(1929): El movimiento internacional del oro, Revista económica, vol. 2, ํ 6, Buenos Aires. Reproducido en Raúl Prebisch. Obras 1919-1948, vol. I, Buenos Aires, Fundación Raúl Prebisch, 1991.

(1930a): El estado económico, Revista económica, vol. 3, $\mathrm{N}^{\circ} 1$, Buenos Aires. Reproducido en Raúl Prebisch. Obras 19191948, vol. I, Buenos Aires, Fundación Raúl Prebisch, 1991.

(1930b): El estado económico, Revista económica, vol. 3, $\mathrm{N}^{\circ}$ 5, Buenos Aires. Reproducido en Raúl Prebisch. Obras 1919-1948, vol. I, Buenos Aires, Fundación Raúl Prebisch, 1991.

(1931a): Redescuento, Decreto-ley del Poder Ejecutivo Nacional, Buenos Aires. Reproducido en Raúl Prebisch. Obras 1919-1948, vol. II, Buenos Aires, Fundación Raúl Prebisch, 1991.

(1931b): Control de cambios, Boletín oficial, Buenos Aires, octubre. Reproducido en Raúl Prebisch. Obras 1919-1948, vol. II, Buenos Aires, Fundación Raúl Prebisch, 1991.

(1932a): Impuesto a los réditos, Boletín oficial. Buenos Aires, enero. Reproducido en Raúl Prebisch. Obras 19191948, vol. II, Buenos Aires, Fundación Raúl Prebisch, 1991.

(1932b): La acción de emergencia en el problema monetario, Revista económica, vol. 5, $\mathrm{N}^{\circ} 2$, Buenos Aires. Reproducido en Raúl Prebisch. Obras 1919-1948, vol. II, Buenos Aires, Fundación Raúl Prebisch, 1991.

(1933 a): La Conferencia Económica y la crisis mundial, Revista económica, vol. 6, $\mathrm{N}^{\circ} 1$, Buenos Aires. Reproducido en Raúl Prebisch. Obras 1919-1948, vol. II, Buenos Aires, Fundación Raúl Prebisch, 1991.

(1933b): El convenio con Gran Bretaña, Diario La Nación, Buenos Aires, 2 de mayo. Reproducido en Raúl Prebisch. Obras 1919-1948, vol. II, Buenos Aires, Fundación Raúl Prebisch, 1991.

(1933c): El retroceso de los precios agropecuarios, Revista económica, vol. $6, \mathrm{~N}^{\circ} 8$, Buenos Aires. Reproducido en Raúl Prebisch. Obras 1919-1948, vol. II, Buenos Aires, Fundación Raúl Prebisch, 1991.

(1934a): El Plan de Acción Económica Nacional, Buenos Aires, Ministerio de Hacienda y Agricultura de la Nación. Reproducido en Raúl Prebisch. Obras 1919-1948, vol. II, Buenos Aires, Fundación Raúl Prebisch, 1991.

(1934b): El momento presente de nuestra economía, Revista económica, vol. 7, $\mathrm{N}^{\circ \mathrm{s}} 1$ al 4, Buenos Aires. Reproducido en Raúl Prebisch. Obras 1919-1948, vol. II, Buenos Aires, Fundación Raúl Prebisch, 1991.

(1934c): La inflación escolástica y la moneda argentina, Diario La Nación, Buenos Aires, 1 al 3 de julio. Reproducido en Raúl Prebisch. Obras 1919-1948, vol. II, Buenos Aires, Fundación Raúl Prebisch, 1991.

(1949): El desarrollo económico de la América Latina y algunos de sus principales problemas, Santiago de Chile, CEPAL. Reproducido en A. Gurrieri. La obra de Prebisch en la CEPAL, México, D.F., Fondo de Cultura Económica, 1982. (1963) : Hacia una dinámica del desarrollo latinoamericano, México, D.F., Fondo de Cultura Económica.

(1972): Proyecto de creación de un Banco Central, Banco Central de la República Argentina, La creación de un Banco Central y la experiencia monetaria argentina entre los años 
1935 y 1943, Buenos Aires. Reproducido en Raúl Prebisch. Obras 1919-1948, vol. II, Buenos Aires, Fundación Raúl Prebisch, 1991.

(1982): El desarrollo económico de la América Latina y algunos de sus principales problemas, A. Gurrieri, La obra de Prebisch en la CEPAL, El trimestre económico: Lecturas, $\mathrm{N}^{\circ} 46$, México, D.F., FCE.

(1983): Cinco etapas de mi pensamiento sobre el desarro1lo. El trimestre económico, vol. L (2), º 198, México, D.F., Fondo de Cultura Económica.

Rodríguez, O. (2001a): Fundamentos del estructuralismo latinoamericano, Comercio exterior, vol. 51, No 2, México, D.F., Banco Nacional de Comercio Exterior (BANCOMEXT).

(2001b): Prebisch: Actualidad de sus ideas básicas, Revista de la CEPAL, $\mathrm{N}^{\mathrm{o}} 75$, Santiago de Chile, CEPAL.
Rodrik, D. (1998): The New Global Economy and Developing Countries, Baltimore, Pennsylvania, Johns Hopkins University Press.

Santa Cruz, H. (1995): La creación de las Naciones Unidas y de la CEPAL, Revista de la CEPAL, N ${ }^{\circ}$ 57, LC/G. 1891-P, Santiago de Chile, CEPAL.

Sprout, R. (1992): El pensamiento de Prebisch, Revista de la CEPAL, $\mathrm{N}^{\mathrm{o}}$ 46, LC/G.1717-P, Santiago de Chile, CEPAL

Viner, J. (1952): International Trade and Economic Development, Illinois, Glencoe.

Weber, M. (1964): Economía y sociedad, México, D.F., Fondo de Cultura Económica..

Williams, J. (1920): Argentine International Trade under Inconvertible Paper Money, Cambridge, Massachusetts, Best Books. 